\title{
IDENTIFIKASI FAKTOR-FAKTOR YANG MEMPENGARUHI INDEKS PEMBANGUNAN MANUSIA DI KALIMANTAN MENGGUNAKAN REGRESI PANEL
}

\section{Identification of The Factors That Influence The Human Development Index In Kalimantan Using Panel Regression}

\author{
Rifka Nurfaiza Zarkasi ${ }^{1}$, Sifriyani $^{2 *}$, Surya Prangga ${ }^{3}$ \\ ${ }^{1,2,3}$ Prodi Statistika, Fakultas Matematika dan Ilmu Pengetahuan Alam, Universitas Mulawarman \\ Jl. Gn. Kelua, Samarinda, 75119, Indonesia \\ Corresponding author e-mail: 2* sifri.stat.unmul@gmail.com
}

\begin{abstract}
Abstrak
Pembangunan merupakan salah satu cara untuk meningkatkan kualitas kehidupan demi terciptanya masyarakat yang sejahtera. Pemerintah terus melakukan pembangunan di segala aspek seperti aspek pendidikan, kesehatan, dan kehidupan yang layak. Untuk mengukur keberhasilan pembangunan salah satu indikator yang bisa digunakan adalah Indeks Pembangunan Manusia (IPM). Dalam perhitungan IPM, telah melibatkan komponen ekonomi maupun non ekonomi. Penelitian ini bertujuan untuk meneliti faktor-faktor yang mempengaruhi IPM Kalimantan pada tahun 2014-2017. Karena data yang digunakan merupakan data panel yaitu gabungan antara data crosssection dan data time-series, maka IPM dimodelkan dengan regresi panel. Untuk mengestimasi model digunakan pendekatan Fixed Effect Model (FEM). Pemodelan IPM menghasilkan nilai $R^{2}$ sebesar 99,54 persen. Hasil penelitian menunjukkan bahwa untuk meningkatkan IPM dapat dilakukan dengan cara meningkatakan angka harapan hidup, rata-rata lama sekolah, harapan lama sekolah, dan pengeluaran per kapita.
\end{abstract}

Kata Kunci : Fixed Effect Model, IPM, regresi data panel

\begin{abstract}
Development is one way to improve the quality of life for the creation of a prosperous society. The government continues to carry out development in all aspects as aspects of education, health, and a decent life. To measure the success of development one indicator that can be used is the Human Development Index (HDI). In the calculation of $H D I$, it has involved economic and non-economic components. This study aims to examine the factors that influence the HDI of Kalimantan in 2014-2017. The data used are panel data that is a combination of cross-section and timeseries data, the HDI is modeled with panel regression. To estimate the model the Fixed Effect Model (FEM) approach is used. HDI modeling resulted in $R 2$ value of 99.54 percent. The results showed that to improve HDI can be done by life expectancy at birth, mean years of schooling, expected years of schooling and general allocation funds.
\end{abstract}

Keywords: Fixed Effect Model, HDI, panel data regression. 


\section{PENDAHULUAN}

Pembangunan menjadi hal yang sangat penting terutama bagi negara yang sedang berkembang. Perbandingan pendapatan dan pembangunan di berbagai negara membuktikan adanya tingkat perbedaan yang relatif besar dalam mengukur taraf kemakmuran diantara negara maju dan negara berkembang. Sumber daya manusia yang berkualitas tinggi sangat dibutuhkan untuk menunjang pembangunan yang sedang berlangsung saat sekarang ini. Pengembangan sumber daya manusia saat ini diarahkan untuk merubah sumber daya manusia yang potensial menjadi tenaga kerja yang produktif [1]. United Nations Development Programme atau UNDP pada tahun 1990 memperkenalkan suatu indikator yang dapat menggambarkan perkembangan manusia secara terukur dan representatif melalui Human Development Report (HDR) atau Indeks Pembangunan Manusia (IPM) yang dipublikasikan secara berkala dalam laporan tahunan. IPM dibentuk oleh tiga elemen dasar, yakni umur panjang dan hidup sehat (a long and healthy life), pengetahuan (knowledge) dan standar hidup layak (a decent standard of living).

Salah satu tolak ukur yang digunakan dalam melihat kualitas hidup manusia adalah Indeks Pembangunan Manusia (IPM) atau Human Development Index yang diukur melalui kualitas tingkat pendidikan, kesehatan dan ekonomi. IPM merupakan indikator penting untuk mengukur keberhasilan dalam upaya membangun kualitas hidup manusia. IPM menjelaskan bagaimana penduduk dapat mengakses hasil pembangunan dalam memperoleh pendapatan, kesehatan dan pendidikan. IPM berkisaran antara 0 hingga 100 dengan rincian IPM yang kecil dari 50 termasuk kategori rendah, IPM dari 50 sampai 80 termasuk kategori sedang/menengah dan IPM yang besar dari 80 termasuk kategori tinggi [2].

Indeks Pembangunan Manusia di Kalimantan dari tahun 2010 sampai dengan 2018 mengalami peningkatan. Capaian ini merupakan agregasi dari tiga dimensi, yaitu umur panjang dan hidup sehat, pengetahuan dan standar hidup layak. Untuk menghitung dimensi umur panjang dan hidup sehat, digunakan indikator Angka Harapan Hidup (AHH) saat lahir. Sedangkan Rata-Rata Lama Sekolah (RLS) dan Harapan Lama Sekolah (HLS) merupakan indikator yang mewakili dimensi pengetahuan. Selanjutnya, dimensi standar hidup layak diwakili oleh indikator Pengeluaran per Kapita Disesuaikan [3].

Metode yang sering digunakan dalam menentukan faktor-faktor yang mempengaruhi IPM adalah metode regresi. Perkembangan metode analisis regresi telah mengalami berbagai kemajuan yang pesat, baik dalam aspek metode estimasi maupun variasi data yang digunakan, perkembangan tersebut tidak terlepas dari kebutuhan terhadap alat analisis yang mampu mengakomodasi berbagai bentuk data antar unit (cross-section), antar waktu (time series) dan penggabungan keduanya yang disebut data panel. Data panel adalah data kombinasi dari data cross-section dan data time series dalam jangka waktu tertentu. Data cross-section merupakan data yang di kumpulkan dalam kurun waktu tertentu dari sampel. Sedangkan data time series adalah data yang mengukur variabel selama periode waktu yang berturut-turut atau pada waktu yang berbeda [4].

Analisis regresi panel adalah analisis yang didasarkan pada data panel untuk mengamati hubungan antara satu variabel dependen dengan satu atau lebih variabel independen [5]. Data panel merupakan gabungan antara data cross-section dan data time series. Pada data panel, unit cross-section yang sama diukur selama beberapa periode waktu. Jadi dapat dikatakan data panel memiliki dimensi ruang dan waktu. Analisis regresi panel dapat digunakan ketika kedua informasi tersebut telah tersedia. Kelebihan lain penggunaan data panel adalah ketersediaan jumlah data yang dianalisis, karena selama ini sebagian besar analisis regresi menggunakan data antar unit (cross-section) atau data antar waktu (time series) saja. Dalam kenyataannya, ketersediaan dua jenis data tersebut sangat terbatas sehingga para peneliti sering mengalami kekurangan data. Selain itu, metode analisis regresi dengan data panel akan memberikan hasil yang lebih baik dari aspek statistik maupun kesesuaian teori [4].

Tujuan dari penelitian ini adalah mendapatkan model regresi panel pada faktor-faktor yang mempengaruhi Indeks Pembangunan Manusia di Kalimantan, mendapatkan nilai signifikansi parameter dengan menggunakan model regresi panel, dan mendapatkan faktor-faktor yang berpengaruh pada Indeks Pembangunan Manusia di Kalimantan. Studi kasus yang digunakan adalah Indeks Pembangunan Manusia di Kalimantan pada tahun 2014-2017. Faktor-faktor yang mempengaruhi Indeks Pembangunan Manusia tercermin oleh beberapa variabel independen diantaranya Angka Harapan Hidup (AHH), Rata-rata Lama Sekolah (RLS), Harapan Lama Sekolah (HLS), Persentase Penduduk Miskin dan Pengeluaran per Kapita. 


\section{METODE PENELITIAN}

\subsection{Data Penelitian}

Penelitian ini menggunakan data Indeks Pembanguan Manusia (IPM), Angka Harapan Hidup (AHH), Harapan Lama Sekolah (HLS), Rata-rata Lama Sekolah (RLS), persentase penduduk miskin dan pengeluaran per kapita di Kalimantan. Teknik pengumpulan data yang digunakan adalah pengumpulan data sekunder karena tidak dilakukan penelitian langsung, melainkan hanya mengambil data yang sudah ada.

\subsection{Analisis Data}

Penelitian ini menggunakan beberapa tahapan analisis yaitu:

1. Membuat statistika deskriptif

2. Melakukan estimasi Common Effect Model (CEM)

Pada model CEM seluruh data digabungkan tanpa mempedulikan waktu dan individu sehingga hanya mempunyai satu data yang terdiri dari variabel dependen dan variabel independen. Persamaan model CEM adalah sebagai berikut[6]:

$$
Y_{i t}=\beta_{0}+\beta^{\prime X_{i t}}+\varepsilon_{i t}
$$

dengan $Y_{i t}$ merupakan variabel dependen pada unit observasi ke-i untuk periode waktu ke-t, $\beta_{0}$ merupakan intersep model, $\beta$ merupakan koefisien slope, $X_{i t}$ variabel independen dan $\varepsilon_{i t}$ merupakan komponen error.

3. Melakukan estimasi Fixed Effect Model (FEM)

Pada model FEM menggunakan teknik penambahan variabel dummy sehingga metode ini disebut model Least Square Dummy Variable (LSDV). Persamaan model FEM adalah sebagai berikut [7]:

$$
Y_{i t}=\sum_{k=1}^{n} \beta_{0_{k}} D_{k i}+\beta^{\prime X_{i t}}+\varepsilon_{i t}
$$

dengan $\beta_{0_{k}}$ merupakan intersep model ke-k dan $D_{k i}$ merupakan variabel dummy.

4. Melakukan estimasi Random Effect Model (REM)

Pada model REM estimasi yang dilakukan adalah model efek acak yang juga disebut sebagai model komponen galat [8]. Perbedaan karakteristik individu dan waktu diakomodasikan pada galat atau error dari model. Random pada error REM perlu diurai menjadi error komponen waktu dan error gabungan. Persamaan model REM adalah sebagai berikut [9]:

$$
Y_{i t}=\beta_{0}+\beta^{\prime} X_{i t}+\varepsilon_{i t} ; \quad \varepsilon_{i t}=u_{i}+v_{t}+w_{i t}
$$

Dengan $u_{i}$ merupakan komponen error cross-section, $v_{t}$ komponen error time-series dan $w_{i t}$ komponen error gabungan.

5. Menentukan model estimasi terbaik dengan uji Chow, uji LM, dan uji Hausman

Pada uji Chow digunakan untuk menentukan penggunaan model FEM atau model CEM menggunakan uji $F$. Uji $F$ adalah sebagai berikut:

$$
F=\frac{(N T-N-k)}{(N-1)} \frac{\left(J K G_{1}-J K G_{2}\right)}{J K G_{2}}
$$

dengan $N$ merupakan banyaknya unit cross-section, $T$ merupakan banyaknya, $k$ merupakan banyaknya variabel independen, $J K G_{1}$ merupakan jumlah kuadrat galat CEM dan $J K G_{2}$ merupakan jumlah kuadrat galat FEM [10]. Daerah kritisnya adalah $H_{0}$ ditolak jika $F_{\text {hitung }}>F_{(N-1),(N T-N-k)}$ dimana

$H_{0}: \beta_{0_{1}}=\beta_{0_{2}}=\cdots=\beta_{0_{N}}=0$ (model yang digunakan CEM)

$H_{1}$ : minimal terdapat satu $\beta_{0_{i}} \neq 0 ; i=1,2, \ldots, N$ (model yang digunakan FEM)

Pada uji Lagrange Multiplier (LM) digunakan untuk menentukan penggunaan model CEM atau model REM. Uji LM adalah sebagai berikut:

$$
L M=\frac{N T}{2(T-1)}\left[\frac{\sum_{i=1}^{N}\left(T \bar{\varepsilon}_{i}\right)^{2}}{\sum_{i=1}^{N} \sum_{i=1}^{T} \varepsilon_{i t}^{2}}-1\right]^{2}
$$

dengan $\varepsilon$ merupakan galat, $i$ merupakan unit observasi dan $t$ merupakan unit periode waktu [10]. Daerah kritisnya adalah $H_{0}$ ditolak jika $L M>\chi_{k}^{2}$ dimana 
$H_{0}: \sigma_{\varepsilon_{i}}^{2}=0$ (model yang digunakan CEM)

$H_{1}: \sigma_{\varepsilon}^{2} \neq 0 ; i=1,2, \ldots, N$ (model yang digunakan REM)

Pada uji Hausman digunakan untuk menentukan penggunaan model REM atau model FEM menggunakan uji Wald. Uji Wald adalah sebagai berikut:

$$
W=\left(\hat{\beta}_{O L S}-\hat{\beta}_{G L S}\right)^{\prime} \Sigma^{-1}\left(\hat{\beta}_{O L S}-\hat{\beta}_{G L S}\right)
$$

Dengan $\hat{\beta}_{O L S}$ merupakan vektor parameter FEM, $\hat{\beta}_{G L S}$ merupakan vektor parameter REM dan $\Sigma^{-1}$ merupakan invers matriks varians-kovarians [10]. Daerah kritisnya adalah $H_{0}$ ditolak jika $W>\chi_{k}^{2}$ dimana:

$H_{0}: \operatorname{corr}\left(X_{i t}, \varepsilon_{i t}\right)=0$ (model yang digunakan REM)

$H_{1}: \operatorname{corr}\left(X_{i t}, \varepsilon_{i t}\right) \neq 0$ (model yang digunakan FEM)

$i=1,2, \ldots, N ; t=1,2, \ldots, T$

6. Melakukan pengujian signifikansi parameter

Pengujian signifikansi parameter dilakukan dalam dua tahap, yaitu pengujian secara serentak dan pengujian secara parsial. Uji serentak digunakan untuk mengevaluasi pengaruh semua variabel independen terhadap variabel dependen, sedangkan uji parsial digunakan untuk membuktikan variabel independen secara individu mempengaruhi variabel dependen.

7. Melakukan pengujian asumsi klasik

Model regresi yang baik adalah model yang memenuhi kriteria BLUE (Best, Linear, Unbiased, dan Estimation). Agar suatu persamaan dapat memenuhi kriteria BLUE, maka data harus memenuhi asumsi yang biasa dikenal dengan uji asumsi klasik [11]. Uji asumsi yang dilakukan adalah uji normalitas, uji multikolinieritas, uji homoskedastisitas, dan uji autokorelasi.

\section{HASIL DAN PEMBAHASAN}

\subsection{Analisis Statistika Deskriptif}

Gambaran data dari variabel yang digunakan secara umum disajikan pada Tabel 1 sebagai berikut:

Tabel 1. Statistika Deskriptif

\begin{tabular}{cccc}
\hline Variabel & Rata-rata & Minimum & Maksimum \\
\hline IPM $(Y)$ & 68,39 & 58,52 & 79,69 \\
\hline AHH $\left(X_{1}\right)$ & 69,96 & 62,09 & 73,97 \\
\hline $\operatorname{RLS}\left(X_{2}\right)$ & 7,88 & 5,19 & 11,03 \\
\hline $\operatorname{HLS}\left(X_{3}\right)$ & 12,27 & 10,25 & 14,92 \\
\hline $\operatorname{PPM}\left(X_{4}\right)$ & 6,59 & 2,46 & 13,71 \\
\hline $\operatorname{PPK}\left(X_{5}\right)$ & 9.943 & 6.105 & 16.271 \\
\hline
\end{tabular}

Dari Tabel 1 dapat dilihat bahwa selama periode 2014-2017 nilai rata-rata pada data Indeks Pembangunan Manusia (IPM) Kabupaten/Kota di Kalimantan adalah 68,39. IPM terendah adalah 58,52, sedangkan IPM tertinggi adalah 79,69.

\subsection{Pemilihan Estimasi Model Regresi Panel}

Hasil estimasi model CEM dapat dilihat pada Tabel 2 seperti berikut:

Tabel 2. Hasil Estimasi Common Effect Model

\begin{tabular}{cc}
\hline Variabel & Koefisien $(\boldsymbol{\beta})$ \\
\hline Intersep & 6,89 \\
\hline$X_{1}$ & $4,13 \times 10^{-5}$ \\
\hline$X_{2}$ & 1,26 \\
\hline Variabel & Koefisien $(\boldsymbol{\beta})$ \\
\hline$X_{3}$ & 1,01 \\
\hline$X_{4}$ & $4,54 \times 10^{-5}$ \\
\hline$X_{5}$ & $1,03 \times 10^{-5}$ \\
\hline
\end{tabular}


Berdasarkan Tabel 2 model regresi panel yang didapatkan dengan estimasi CEM adalah

$$
\hat{Y}_{i t}=6,89+4,13 \times 10^{-5} X_{1_{i t}}+1,26 X_{2_{i t}}+1,01 X_{3_{i t}}+\left(4,54 \times 10^{-5}\right) X_{4_{i t}}+\left(1,03 \times 10^{-5}\right) X_{5_{i t}}
$$

Hasil estimasi model FEM dapat dilihat pada Tabel 3 seperti berikut:

Tabel 3. Hasil Estimasi Fixed Effect Model

\begin{tabular}{cc}
\hline Variabel & Koefisien $(\boldsymbol{\beta})$ \\
\hline$X_{1}$ & 0,4 \\
\hline$X_{2}$ & 1,43 \\
\hline$X_{3}$ & 1,12 \\
\hline$X_{4}$ & $-0,02$ \\
\hline$X_{5}$ & $9,05 \times 10^{-6}$ \\
\hline
\end{tabular}

Berdasarkan Tabel 3 model regresi panel yang didapatkan dengan estimasi FEM adalah

$$
\hat{Y}_{i t}=\beta_{0_{i}} D_{i}+0,4 X_{1_{i t}}+1,43 X_{2_{i t}}+1,12 X_{3_{i t}}-0,02 X_{4_{i t}}+\left(9,05 \times 10^{-6}\right) X_{5_{i t}}
$$

Hasil estimasi model REM dapat dilihat pada Tabel 4, seperti berikut:

Tabel 4. Hasil Estimasi Random Effect Model

\begin{tabular}{cc}
\hline Variabel & Koefisien $(\boldsymbol{\beta})$ \\
\hline intersep & 6,99 \\
\hline$X_{1}$ & 0,40 \\
\hline$X_{2}$ & 1,37 \\
\hline$X_{3}$ & 1,12 \\
\hline$X_{4}$ & $-1,62 \times 10^{-4}$ \\
\hline$X_{5}$ & $9,46 \times 10^{-6}$ \\
\hline
\end{tabular}

Berdasarkan Tabel 4 model regresi panel yang didapatkan dengan estimasi REM adalah

$$
\hat{Y}_{i t}=6,99+0,40 X_{1 i t}+1,37 X_{2_{i t}}+1,12 X_{3 i t}-\left(1,62 \times 10^{-4}\right) X_{4_{i t}}+\left(19,46 \times 10^{-6}\right) X_{5_{i t}}
$$

Pada uji Chow didapatkan nilai $p$-value sebesar $2,2 \times 10^{-16}$ dan lebih kecil dari $\alpha=5 \%$, maka model estimasi yang baik adalah model FEM. Karena model yang terpilih adalah model FEM, maka dilanjutkan ke Uji Hausman. Pada uji Hausman didapatkan nilai $p$-value sebesar $1,06 \times 10^{-7}$ dan lebih kecil dari $\alpha=5 \%$, maka model estimasi yang baik adalah model FEM. Sehingga model regresi panel yang terbaik untuk Indeks Pembangunan Manusia diestimasi dengan model FEM.

Berdasarkan pengujian signifikansi parameter, didapatkan nilai $F$ sebesar 581,71 dan lebih besar dari $F_{(60) ;(163) ; 0,05}=1,448$ maka terdapat beberapa variabel independen yang berpengaruh atau secara serentak variabel independen berpengaruh pada variabel dependen dan didapatkan nilai probabilitas statistik $t$ pada uji parsial dengan kesimpulannya sebagai berikut:

Tabel 2. Uji Parsial

\begin{tabular}{cccc}
\hline Variabel & Koefisien $(\boldsymbol{\beta})$ & $\boldsymbol{p}$-value & Kesimpulan \\
\hline$X_{1}$ & 0,413 & $2 \times 10^{-16}$ & Berpengaruh \\
\hline$X_{2}$ & 1,262 & $2 \times 10^{-16}$ & Berpengaruh \\
\hline$X_{3}$ & 1,013 & $2 \times 10^{-16}$ & Berpengaruh \\
\hline$X_{4}$ & 0,005 & 0,694 & Tidak Berpengaruh \\
\hline$X_{5}$ & 0,001 & $2 \times 10^{-16}$ & Berpengaruh \\
\hline
\end{tabular}

Berdasarkan Tabel 2 didapatkan bahwa pada taraf signifikansi $\alpha=5 \%$ variabel $X_{4}$ tidak berpengaruh signifikan terhadap variabel dependen sedangkan variabel $X_{1}, X_{2}, X_{3}$ dan $X_{5}$ berpengaruh signifikan terhadap variabel dependen. Maka model estimasi FEM menjadi sebagai berikut: 


$$
Y_{i t}=\beta_{0 i} D_{i}+0,4 X_{1_{i t}}+1,43 X_{2_{i t}}+1,12 X_{3_{i t}}+9,05 \times 10^{-6} X_{5_{i t}}
$$

Pada pengujian koefisien determinasi didapatkan nilai $R^{2}$ sebesar 0,9954 . Nilai ini memiliki arti bahwa variabel-variabel independen mempengaruhi variabel dependen sebesar 99,54\% sedangkan 0,46\% sisanya dipengaruhi oleh variabel-variabel lain yang belum masuk dalam model.

Berdasarkan pengujian asumsi klasik, pada uji normalitas didapatkan nilai p-value sebesar 0,064 dan lebih besar dari $\alpha=5 \%$ maka model FEM residual berdistribusi normal. Pada uji multikolinieritas didapatkan nilai VIF $X_{1}=1,346, X_{2}=3,747, X_{3}=2,748$ dan $X_{5}=2,101$. Karena nilai VIF masingmasing kurang dari 10, maka dapat diketahui bahwa model FEM tidak terjadi multikolinieritas. Pada uji homoskedastisitas didapatkan nilai $p$-value sebesar 0,85 dan lebih besar dari $\alpha=5 \%$ maka model FEM terjadi homoskedastisitas pada residual. Pada uji autokorelasi didapatkan nilai $p$-value sebesar 0,064 dan lebih besar dari $\alpha=5 \%$ maka model FEM tidak terdapat autokorelasi.

\section{KESIMPULAN} berikut:

Model regresi panel diestimasi dengan Fixed Effect Model (FEM) dan didapatkan model sebagai

$$
\hat{Y}_{i t}=\beta_{0_{i}} D_{i}+0,4 X_{1_{i t}}+1,43 X_{2_{i t}}+1,12 X_{3 i t}+9,05 \times 10^{-6} X_{5_{i t}}
$$

Model ini dapat diinterpretasikan bahwa bertambahnya Angka Harapan Hidup (AHH) sebesar 1 tahun akan meningkatkan Indeks Pembangunan Manusia (IPM) sebesar 0,4. Bertambahnya Rata-rata Lama Sekolah (RLS) sebesar 1 tahun akan meningkatkan IPM sebesar 1,43. Bertambahnya Harapan Lama Sekolah (HLS) sebesar 1 tahun akan meningkatkan IPM sebesar 1,12. Bertambahnya Pengeluaran per

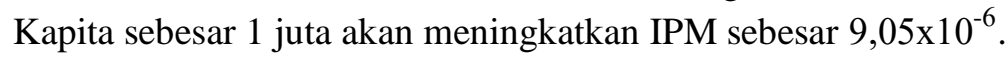

Berdasarkan hasil pengujian signifikansi parameter didapatkan nilai $F$ sebesar 581,71 dan lebih besar dari $F_{(60) ;(163) ; 0,05}=1,448$ maka secara serentak variabel independen berpengaruh pada variabel dependen, pada uji parsial didapatkan bahwa variabel $X_{4}$ tidak berpengaruh signifikan terhadap variabel dependen sedangkan variabel $X_{1}, X_{2}, X_{3}$ dan $X_{5}$ berpengaruh signifikan terhadap variabel dependen dan variabelvariabel independen mempengaruhi variabel dependen berdasarkan nilai koefisien determinasi $\left(R^{2}\right)$ adalah sebesar $99,54 \%$ sedangkan $0,46 \%$ sisanya dipengaruhi oleh variabel-variabel lain yang belum masuk dalam model.

Berdasarkan hasil pengujian didapatkan faktor-faktor yang mempengaruhi Indeks Pembangunan Manusia di Kalimantan adalah Angka Harapan Hidup (AHH), Rata-rata Lama Sekolah (RLS), Harapan Lama Sekolah (HLS) dan Pengeluaran per Kapita.

\section{DAFTAR PUSTAKA}

[1] Elfindri dan Nasri, Bachtiar, Ekonomi Ketenagakerjaan. Andalas, Padang: University Press, 2004

[2] Mirza, Denni Sulistio, "Pengaruh Kemiskinan, Pertumbuhan Ekonomi dan Belanja Modal Terhadap Indeks Pembanguan Manusia di Jawa Tengah Tahun 2006-2009," Economics Development Analysis Journal, vol.1, no.2, 2012.

[3] BPS, Indeks Pembangunan Manusia 2014 Metode Baru, Jakarta: Badan Pusat Statistik, 2014.

[4] Sriyana, Jaka, Metode Regresi Data Panel, Yogyakarta: Ekosiana, 2014.

[5] Jaya, I. G. N. M. dan Sunengsih, N., "Kajian Analisis Regresi dengan Data Panel," Prosiding Seminar Nasional Penelitian, Yogyakarta: Universitas Negeri Yogyakarta, 2009.

[6] Gujarati, Damodar N., Basic Econometrics, Fourth Edition, New York: The McGraw-Hill Companies, 2004.

[7] Greene, William H., Econometrics Analysis, 6th Edition, New Jersey: Prentice Hall, 2007.

[8] Setiawan dan Kusrini, Ekonometrika, Yogyakarta: Penerbit ANDI, 2010.

[9] Nachrowi, D. N. dan H. Usman, Pendekatan Populer dan Praktis Ekonometrika untuk Analisis Ekonomi dan Keuangan, Jakarta: Lembaga Penerbit FE UI, 2006.

[10] Widarjono, Agus, Ekonometrika Teori dan Aplikasi untuk Ekonomi dan Bisnis, Edisi Kedua, Yogyakarta: Penerbit Ekonisial FE UI, 2009.

[11] Yudiatmaja, F., Analisis Regresi dengan Menggunakan Aplikasi Komputer Statistika SPSS, Jakarta: Gramedia Pustaka Utama, 2013. 